\title{
Guidelines of the Polish Psychiatric Association - Wroclaw Division, the Polish Society of Family Medicine and the College of Family Physicians in Poland for diagnosis and treatment of depressive disorders in primary health care
}

\author{
PATRYK PIOTROWSKI 1, 2, A, B, D-F TOMASZ MACIEJ GONDEK 1, 2, 3, A, B, D-F, \\ JOANNA RYMASZEWSKA ${ }^{1,2,0, \mathrm{E}}$, JAN ALEKSANDER BESZŁEJ 1, 2, D, \\ SŁAWOMIR CZACHOWSKI 4, 5, D, E, HENK PARMENTIER ${ }^{6,7, D, ~ E, ~ D O N A T A ~ K U R P A S ~ 2, ~ 8, ~ 9, ~ A, ~ в, ~ D-F ~}$
}

\author{
${ }^{1}$ Department of Psychiatry, Wroclaw Medical University, Poland \\ 2 Polish Psychiatric Association - Wroclaw Division, Poland \\ ${ }^{3}$ Specialty Training Section, Polish Psychiatric Association, Poland \\ ${ }^{4}$ Department of Clinical Psychology, Nicolaus Copernicus University in Torun, Poland \\ ${ }^{5}$ College of Family Physicians in Poland \\ ${ }^{6}$ Medical School, Nova University, Lisbon, Portugal \\ ${ }^{7}$ WONCA Working Party on Mental Health \\ ${ }^{8}$ Family Medicine Department, Wroclaw Medical University, Poland \\ ${ }^{9}$ Polish Society of Family Medicine, Poland
}

A - Study Design, B - Data Collection, C - Statistical Analysis, D - Data Interpretation, E - Manuscript Preparation, F - Literature Search, G - Funds Collection

\begin{abstract}
Summary Mental disorders are common among patients seen by primary care physicians. The most common ones are: mood disorders, anxiety disorders and somatic disorders. Psychological problems often coexist with somatic illnesses, negatively affecting their natural course, adherence to medicines and treatment, and thus the effectiveness of treatment. Apart from biological determinants, such as genetic load, somatic disease burden and treatment options, depressive disorders are also linked to socio-demographic factors. The multitude of issues that require attention from the physician during routine medical consultations makes it difficult to diagnose and decide on appropriate treatment. Screening tools with proven psychometric parameters can facilitate this process. Most patients with unipolar mood disorders can be treated within the primary care setting. They are seeking help from their well-known family physicians and often do not require a psychiatric consultation. It should be emphasized that the vast majority of primary care patients report symptoms of psychosomatic disorders that are aggravated by daily stressful situations. Before starting diagnostic and therapeutic actions, it is advisable to extend the consultation time, analyze their family, financial and professional situation and convince them to use stress management techniques, as well as to persuade them to change perception of the environment and avoid negative habits in life and nutrition. If there is no improvement of the depressive symptoms after 2 to 4 weeks, other therapeutic strategies should be considered. In this paper, the authors propose simplified regimens and indicate the possibilities and limitations of the treatment of mental health disorders in the primary health care setting.

Key words: primary health care, depression, mood disorders, antidepressant treatment.
\end{abstract}

Piotrowski P, Gondek TM, Rymaszewska J, Beszłej JA, Czachowski S, Parmentier H, Kurpas D. Guidelines of the Polish Psychiatric Association - Wroclaw Division, the Polish Society of Family Medicine and the College of Family Physicians in Poland for diagnosis and treatment of depressive disorders in primary health care. Fam Med Prim Care Rev 2017; 19(3): 335-346, doi: https://doi.org/10.5114/ fmpcr.2017.69300.

\section{Background}

In 1990, depression was the fourth cause of disability in the world, after upper respiratory tract infections, diarrhea and perinatal complications. It is estimated that by 2020, depression will rank second after ischemic heart disease [1]. Depression is currently the second most common cause of health loss (after back pain) in Central Europe [2]. Regardless of gender, the prevalence of major depression in the general population in Poland is estimated at $3 \%$. This percentage, although lower than previously shown in other European countries, includes, after extrapolation, 766.2 ( $\mathrm{Cl}$ 693-840) thousands of Poles [3-5].

In Poland, there are no restrictions or limits to access psychiatric health care or for a primary care physician to refer pa- tients with psychosocial problems to psychiatrists. This does not change the fact that patients primarily seek help in family physician surgeries. It is estimated that about $30 \%$ of people with symptoms of depression consult a primary care physician [6, 7]. This is due to the presence of non-specific somatic symptoms that are often the principal presenting symptoms of depression, or co-morbid psychiatric disorders, such as depression and anxiety disorders [8]. The study conducted in Spain by Roca et al. found that $53.6 \%$ of patients reporting to primary care physicians revealed mental disorders, such as depression $-35.8 \%$, anxiety disorders $-25.6 \%$, and somatic disorders $-28.8 \%$. In the study group, $30.3 \%$ of patients had more than one mental disorder, $13.8 \%$ - two, $8.2 \%$ - three, $5.6 \%$ - four, and $2.7 \%$ - five or more. Depression and anxiety disorders were the most common (19.1\%), depression and somatic disorders occurred 
in $18.6 \%$, while anxiety and somatic disorders were reported in $14.8 \%$. The presence of all three diagnostic categories was confirmed in as much as $11.5 \%$ [6].

In addition to the co-occurrence of psychiatric disorders, a number of studies have shown that chronic metabolic, respiratory, cardiovascular, musculoskeletal and neurological disorders are more common in patients with mental disorders [9-11]. At the same time, the presence of psychiatric disorders in a person suffering from somatic disorders worsens the course of the underlying disease, makes prognosis less favorable and increases the risk of complications and death $[12,13]$. Co-morbidity is associated with less effective treatment, greater use of medical services, increased cost of treatment, reduced physician-patient collaboration and frequent non-compliance to treatment [14-16]. In Poland, the percentage of primary care patients diagnosed with depressive symptoms is high: in the study of 2007, over 7,000 patients (23.3\%) met the ICD-10 diagnostic criteria for depression [17].

\section{Methodology}

Experts from the Polish Psychiatric Association - Wroclaw Division, Polish Society of Family Medicine and College of Family Physicians in Poland performed a detailed review of published evidence regarding the diagnosis and treatment of depressive disorders in primary care. In order to propose a concise and useful set of guidelines on the diagnosis and treatment of the most common affective disorders in the primary care setting, the authors analyzed the ICD-10 diagnostic criteria, as well as browsed the PubMed database using combinations of keywords, such as: "primary care", "general practice", "screening", "treatment" and "depression", "depressive episode", "dysthymia" or "bipolar affective disorder". The papers regarding screening, diagnostic criteria and treatment of affective disorders deemed useful for the purpose of the article by two or more authors have been taken into consideration and utilized in one of the guidelines' sections.

\section{Diagnostic procedures}

\section{Symptoms}

\section{Depression}

In Poland, according to the ICD-10 classification of mental and behavioral disorders, depression can take the form of a depressive episode (F32.X) or recurrent depressive disorder (F33.X). The main reasons to suspect a depressive disorder are the duration of symptoms (at least 2 weeks), a negative history of mania or hypomania, the lack of an organic cause and no evidence for the use of psychoactive substances that could worsen one's mood, or the withdrawal of such substances.

The basic symptoms of depression are: 1) low mood, increased feelings of sadness or hopelessness; 2 ) loss of interest and anhedonia, i.e. inability to experience joy and pleasure in situations that have so far been associated with these emotions; and 3 ) reduced energy and fatigue. It is essential to recognize at least 2 of the 3 listed symptoms. In addition, it is necessary to diagnose complementary symptoms so that the total number of symptoms plus basic symptoms is at least 4 . Complementary symptoms are: 1 ) low self-esteem; 2) excessive or unjustified guilt; 3) recurring suicidal thoughts or any behavioral symptoms that are marked by actions leading to the deprivation of life; 4) decreased concentration; 5) agitation or motion impairment; 6) sleep disturbance; and 7) increase or decrease in appetite with an accompanying change in weight.

Up to two-thirds of patients in primary health care present somatic symptoms [18]. The greater the number of somatic complaints, the more likely it is that the patient has depression rather than a somatic cause for the symptoms.

Depending on the number of symptoms and the level of daily functioning, it is possible to diagnose a mild (F3X.0), moderate (F3X.1) or severe depressive episode without psychotic symptoms (F3X.2).

In a mild depressive episode, the total number of symptoms is at least 4; moderate - if there are at least 6 of them and there are already significant difficulties in functioning; while severe - when there are at least 8 symptoms. When the criteria are met for a severe depressive episode, accompanied by mood-adequate delusions or depressive stupor, the diagnosis is that of severe depression with psychotic symptoms (F3X.3), which is an indication for an urgent psychiatric admission.

An episode of depression may occur for the first time in a patient's life (F32.X diagnosis) or appear as an exacerbation of a recurrent depressive disorder (F33.X diagnosis) - The diagnosis of a recurrent disorder is made if there is at least one episode of depression that has occurred in the past, followed by at least 2 months of remission [19].

\section{Somatic syndrome}

According to the ICD-10 classification, a somatic syndrome, also known as melancholy depression, is not a separate entity, but a diagnosis complementing a depressive episode. It can be indicated by adding a " 1 " as the fifth sign to the diagnostic ICD-10 code (F3X.X1). The symptoms of somatic syndrome include: 1) loss of interest or ability to experience pleasure; 2 ) lack of emotional reactions to events that previously triggered emotions; 3 ) early waking; 4) severe mood deprivation in the morning; 5) agitation or motion impairment; 6) decrease in appetite; 7) weight loss; 8 ) decrease in libido. There must be at least 4 of these symptoms present to diagnose the syndrome [19].

\section{Dysthymia}

Dysthymia (F34.1) is a chronic mood condition lasting for at least 2 years, but not as severe as a mild depressive episode. Periods of improvement last no longer than a few weeks, and no episodes of mania or hypomania occur in its course. In order to make a diagnosis of dysthymia, there must be at least 3 of the following symptoms: 1) decreased energy; 2) insomnia; 3) low self-esteem; 4) difficulty concentrating; 5) weepiness; 6 ) loss of sexual desire and pleasure; 7) sense of helplessness; 8) failure to deal with daily tasks; 9) remembrance of past or pessimistic perception of the future; 10 ) social withdrawal; 11) reduced forthcomingness [19].

The main symptoms of the selected disorders, including those with depressive symptoms coexisting with anxiety and depressive symptoms due to situational reactions, are summarized in Table 1.

The scheme of management of patients with mood deprivation and suspicion of depression or dysthymia is presented in Figure 1. 


\begin{tabular}{|c|c|c|c|}
\hline $\begin{array}{l}\text { Depressive disorders } \\
\text { (F32-F33) }\end{array}$ & Dysthymia (F34.1) & $\begin{array}{l}\text { Organic depressive disorders } \\
\text { (F06.32) }\end{array}$ & $\begin{array}{l}\text { Bipolar affective disorder } \\
\text { (F30-F31) }\end{array}$ \\
\hline $\begin{array}{l}\text { 3. There are } \geq 2 \text { of the following } \\
\text { symptoms for } \geq 2 \text { weeks: } \\
\text { - mood deprivation, } \\
\text { - loss of interest and ability } \\
\text { to experience joy (anhe- } \\
\text { donia), } \\
\text { - decrease in energy level. } \\
\text { 4. There are the following } \\
\text { symptoms for } \geq 2 \text { weeks so } \\
\text { that the total number of } \\
\text { symptoms is } \geq 4 \text { : } \\
\text { - weakening of concentra- } \\
\text { tion and attention, } \\
\text { - low self-esteem and self- } \\
\text {-confidence, } \\
\text { - the feeling of guilt and low } \\
\text { value, } \\
\text { - pessimistic, gloomy vision } \\
\text { of the future, } \\
\text { - suicidal thoughts and ac- } \\
\text { tions, } \\
\text { - sleep disorders, } \\
\text { - decreased appetite. }\end{array}$ & $\begin{array}{l}\text { 1. Period } \geq 2 \text { years of constant } \\
\text { or recurrent mood depriva- } \\
\text { tion. Possible, periodic mood } \\
\text { equalization rarely lasts } \\
\text { more than a few weeks. No } \\
\text { episodes of hypomania. } \\
\text { 2. None or almost none of the } \\
\text { depressive episodes present } \\
\text { at this time is sufficiently } \\
\text { severe to meet the criteria } \\
\text { for a mild depressive episode } \\
\text { (F } 33.0) \text {. } \\
\text { 3. Sometimes, there are } 3 \text { or } \\
\text { more of the following symp- } \\
\text { toms: } \\
\text { - decreased energy or activ- } \\
\text { ity, } \\
\text { - sleep disturbance, } \\
\text { - low self-esteem and the } \\
\text { sense of no adaptation, } \\
\text { - disturbed concentration, } \\
\text { - weepiness, } \\
\text { - decreased interest in sex } \\
\text { or satisfaction with sexual } \\
\text { activity and other pleasant } \\
\text { activities, } \\
\text { - a sense of helplessness or } \\
\text { worry, } \\
\text { - an impression that every- } \\
\text { day difficulties and respon- } \\
\text { sibilities are impossible to } \\
\text { handle, } \\
\text { - pessimism about the future } \\
\text { or an overestimation of } \\
\text { the past, } \\
\text { - social withdrawal, reduc- } \\
\text { tion in forthcomingness. }\end{array}$ & $\begin{array}{l}\text { 1. Objectively or historically con- } \\
\text { firmed disease, brain damage } \\
\text { or dysfunction, or somatic } \\
\text { disorders known to cause } \\
\text { brain impairment. } \\
\text { 2. There is a connection } \\
\text { between the appearance or } \\
\text { exacerbation of depressive } \\
\text { disorders and their underlying } \\
\text { disease, damage or dysfunc- } \\
\text { tion of the brain. } \\
\text { 3. Removal of the probable rea- } \\
\text { son causes a return to health } \\
\text { or a significant improvement } \\
\text { in mood. } \\
\text { 4. There is insufficient evidence } \\
\text { suggesting other causes of } \\
\text { depression. } \\
\text { 5. They are not related to the } \\
\text { use of psychoactive sub- } \\
\text { stances. } \\
\text { 6. Meeting the criteria for } 1 \\
\text { of the depressive disorders } \\
\text { (F32-F33). }\end{array}$ & \multirow{3}{*}{ 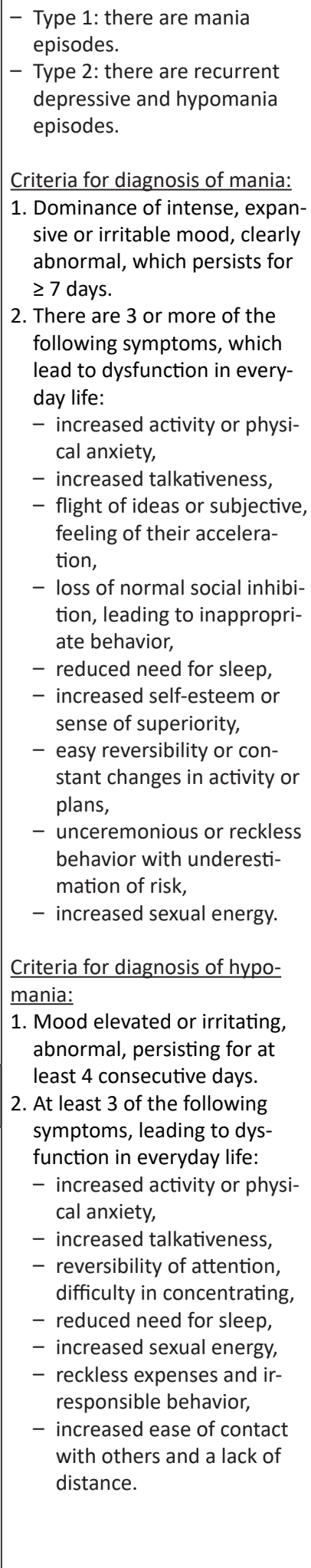 } \\
\hline $\begin{array}{l}\text { Adjustment disorders } \\
\text { (F43.2) }\end{array}$ & $\begin{array}{l}\text { Mixed anxiety and depressive } \\
\text { disorders (F41.2) }\end{array}$ & $\begin{array}{l}\text { Residual affective disorders } \\
\text { (F1X.72) }\end{array}$ & \\
\hline $\begin{array}{l}\text { 2. There are symptoms of } \\
\text { affective disorders (F30-F39), } \\
\text { neurosis (F40-F48) or behav- } \\
\text { ioral disorders (F91.X), but the } \\
\text { criteria for diagnosing these } \\
\text { disorders are not met. }\end{array}$ & $\begin{array}{l}\text { 1. There are symptoms of both } \\
\text { depression and anxiety, but } \\
\text { they do not meet the criteria for } \\
\text { separate anxiety disorders or } \\
\text { depression. }\end{array}$ & $\begin{array}{l}\text { 1. Depressive disorders in the } \\
\text { course of addiction - meet the } \\
\text { criteria for depressive disorders } \\
\text { (F32-F33) and have a clear } \\
\text { relationship with the use of } \\
\text { psychoactive substances. }\end{array}$ & \\
\hline
\end{tabular}

Based on the ICD-10 classification of mental disorders and behavioral disorders. Research diagnostic criteria. Cracow-Warsaw: University Medical Publishing House „Vesalius”, Institute of Psychiatry and Neurology; 1998. 


\section{Suspicion of depression or dysthymia}

Do $\mathbf{2}$ or $\mathbf{3}$ of the following symptoms occur for $\geq \mathbf{2}$ weeks?:

- mood deprivation,

- loss of interest and anhedonia,

- loss of vital energy

\section{Yes}

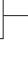

Do the following symptoms occur for $\geq 2$ weeks and together

with the above mentioned symptoms (upper box) amount $\geq 4$ ?:

- low self-esteem,

- excessive or unjustified guilt,

- suicidal behavior or recurring suicidal thoughts,

- reduced concentration,

- agitation or motion inhibition,

- sleep disorder,

- increase or decrease in appetite with change in weight

Can the symptoms be related to somatic illness or psychoactive substances?

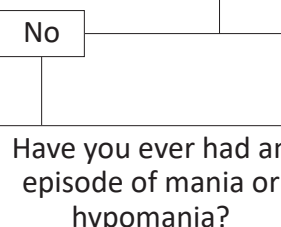
hypomania?

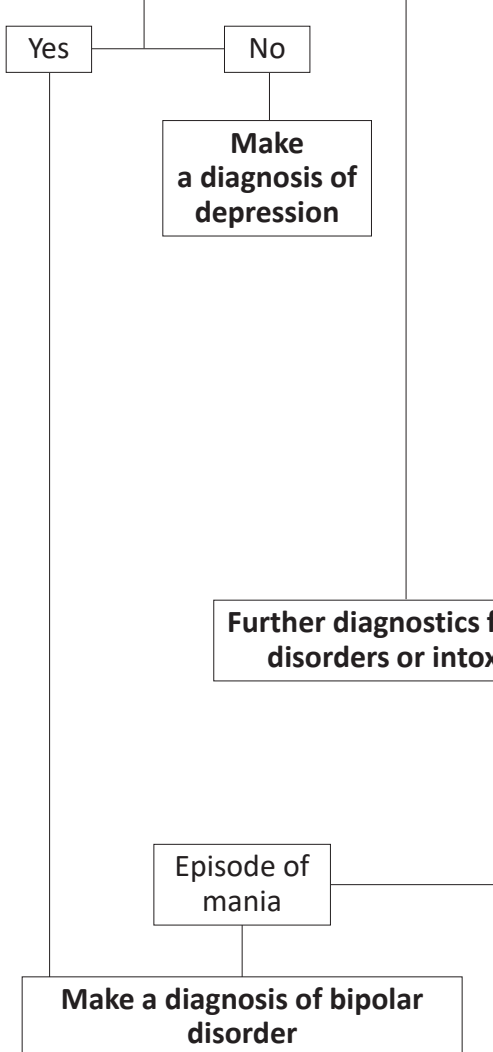

\section{Yes}

Can the symptoms be related to somatic illness or psychoactive substances?

Do $\geq 2$ of the following symptoms occur for $\geq 2$ years, with possible remission periods of $\leq \mathbf{2}$ months?:

- reduced energy,

- insomnia,

- low self-confidence,

- difficulties in concentration,

- tearfulness,

- loss of sexual desire and anhedonia,

- feeling of helplessness,

- not dealing with everyday tasks,

- remembering the past or pessimistic perception of the future,

- social withdrawal,

- reduced forthcomingness

\section{Yes}

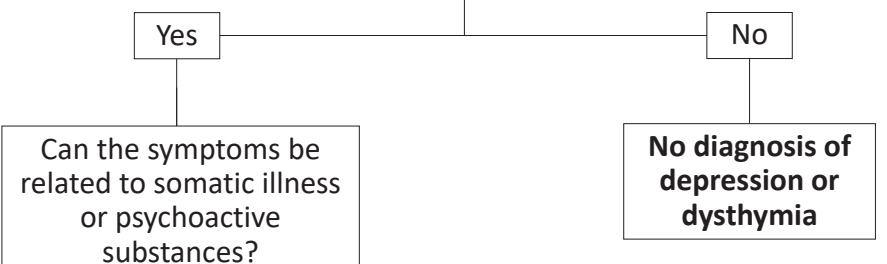

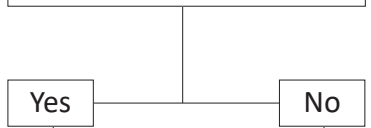

No

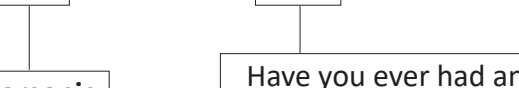

episode of mania or hypomania? 
Treatment of depression by primary care physicians can be safely and effectively commenced while observing the following precaution:

1) the is no doubt about the diagnosis of depression,

2) the symptoms are mild to moderate,

3) mild symptoms may be treated with self-help and/or exercise and/or CBT,

4) there is history of good response to antidepressants in the past,

5) there is no clear risk of suicide or self-harm.

If the above criteria are met, the treatment of depression can be started by the primary care clinician. In the case of a serious threat to health or the life of the patient, the patient should be referred to the admission room of the nearest psychiatric hospital, where a psychiatrist can assess the patient's mental state, and if the patient refuses treatment or is considered to be a risk to him/herself or others, the psychiatrist can consider the possible grounds for applying the provisions of the Mental Health Act, allowing for hospitalization against the will of the patient.

\section{Medical history}

Sole observation of the patient entering the primary care clinic can provide a lot of important information; however, the key criterion for diagnosis is to conduct a thorough and objective examination. As mentioned, depression is a frequent problem among patients reporting to primary care units. Unfortunately, time constraints make it difficult to discuss with each patient all the important issues related to his/her mental state.

For this reason, short screening questionnaires have been developed to help to make the diagnosis of depression. These questions ought to be asked by doctors during the routine taking of a medical history:

1. During the past month, have you often been bothered by feeling down, depressed or a feeling of hopeless?

2. During the past month, have you often been bothered by little interest or pleasure in doing things?

The use of these two screening questions alone showed a sensitivity and specificity of $97 \%$ and $67 \%$, respectively, when tested in a primary care setting on patients $[20,21]$.

If one obtains the answer "yes" to any of the two questions above, supplementation of the screening examination with a third question:

3. "Is there something you would like me to help you with?"

significantly improves the specificity of screening [22]. If the answer to the third question is "no", then it is highly probable that the patient is not depressed [23]. In the event of a "yes" answer to the first and/or second question, a thorough medical history should be taken to diagnose depression or other psychiatric disorders. Other more comprehensive screening tools, like the 9-question Patient Health Questionnaire (PHQ-9), HADS or BDI, can be used as well (described below) [24-26].

When taking a medical history, it is worth asking about the basic symptoms of depression listed in the criteria and less directly expressed in the screening questions mentioned above. The mnemonic method of remembering the most important symptoms of depression is to develop the shortcut SAD SPACE:

S - Suicidal thoughts and tendencies,

A - Anhedonia and the loss of interest,

D - Disappointment to yourself or others,

S-Sleep, shortened or excessively long,

P - Physical activity, reduced or increased,

A - Appetite, reduced or increased,

C-Concentration, weakened,

E - Energy, reduced.
If the patient shows symptoms of depression, one should determine the severity and duration of the symptoms or whether they have a temporary reaction to an adverse or traumatic life event. The use of psychoactive substances should be established, since this may lead to a diagnosis other than depression (see Table 1). It is extremely important to take a thorough medical history for chronic physical conditions, as their co-morbidity with depression is frequent, e.g. $51 \%$ of patients with Parkinson's disease, $42 \%$ of patients with malignancies, $27 \%$ of patients with diabetes, $25 \%$ of patients after myocardial infarction, $23 \%$ of patients after stroke, $17 \%$ of patients with coronary artery disease, $12 \%$ of patients with HIV infection, $11 \%$ of patients with Alzheimer's disease, as well as those with thyroid diseases and other endocrinological conditions, endocrinopathies, connective tissue disorders and electrolyte abnormalities will have co-morbid depression [27].

Particular attention should be paid to individuals who are at risk of developing depression. Risk factors of depression include, but are not limited to: female gender, middle and senior age (the highest risk is between the age from 40 to 64 years), divorce or widowhood, low socio-economic status and genetic factors $[28,29]$. It is obviously very important to take a history about the socio-economic situation of the patient and the burden of mental disorders in the family.

An important area to ask the patient about is the use of medication, many of which may worsen mood and other symptoms of depression. Alcohol and other psychoactive substances are also associated with a higher incidence of depression and a higher risk of suicide, although the association between depression and alcohol addiction is not as strong as in bipolar affective disorder [30-32]. In Poland, $10.9 \%$ of subjects abuse alcohol, including $18.6 \%$ of men. The highest proportion of abusers was found among men aged $40-49$ years - as much as $24.6 \%$ [33]. The use of psychoactive substances, including alcohol, reduces the effectiveness of therapy, worsens the physician-patient interaction and aggravates depressive symptoms due to the depressiogenic effects of substances during active use and during withdrawal.

\section{Suicidal risk}

The comprehensive risk assessment of suicide risk is primarily a psychiatrist's task; however, a basic suicide risk assessment needs to be performed by every physician, not only in those primary care, especially at the beginning and during treatment. The question about suicidal thoughts and tendencies is the most important when assessing the patient's mental state, especially in the presence of risk factors: male, over 40 years of age, positive psychiatric family history, suicidal attempt in the past, major depression, hopelessness, unemployment, social isolation, co-morbidity, as well as anxiety disorders and abuse of alcohol or other psychoactive substances [34].

In the absence of experience in the assessment of suicidal risk, it is useful to apply questions about suicidal behaviors as described in the Polish version of the MINI International Neuropsychiatric Interview 5.0.0:

1. Have you felt in the past month that it would be better to die or you wished to die?

2. Did you want to hurt yourself during the last month?

3. Have you thought about suicide in the last month?

4. Have you planned suicide during the last month?

5. Have you tried to commit suicide during the last month?

6. Have you ever attempted suicide during your whole life?

If the answer was "yes" only to question 1, 2 or 6 - suicide risk is low. If the answer "yes" was given only to question 3 or together with questions 2 and 6 - suicide risk is average. If the answer "yes" was given only to question 4 or only 5 or together with questions 3 and 6 - suicide risk is high [35]. 
The management of depression by the family doctor should be based on the level of suicidal risk, contact with the patient, the level of cooperation and the availability of social support networks.

\section{Physical examination}

Many somatic disorders may result in symptoms of lowered mood, energy loss or changes in the patient's psychomotor activity. It is important to carry out an examination for somatic changes in the course of conditions that may be associated with an increased risk of depression co-morbidity (e.g. Parkinson disease, SM, but also anemia, cardiovascular disease, thyroid diseases, carcinoma etc.), with particular emphasis on a neurological examination. However, during a routine physical examination, attention should be paid to the features that may be associated with mood deprivation: slowing of motor skills, difficulty in executing commands related to distraction, depressed facial expressions, weepiness, but also complaints about various non-specific aches, including headaches and symptoms of pressure in the neck and shoulders, especially if the patient is more likely than average to visit a family doctor surgery (more than four times a year) and demands a number of additional tests, with no improvement in health despite multidirectional treatment.

\section{Additional examinations}

\section{Laboratory tests}

In every patient with depressive symptoms, the following supplementary tests are recommended: Full Blood Count including differentials, electrolytes and renal function, liver function, thyroid function tests, CRP and electrocardiogram. More specialized investigations can by organized by a psychiatrist, such as cortisol levels, neuroimaging and electroencephalogram [36].

Numerous data suggests the presence of mood deprivation in the course of hypothyroidism (also subclinical); therefore, screening of thyroid hormone levels is recommended in patients with suspected depression [37]. Recently, however, analyses have shown that in patients without thyroid disease, a subclinical decrease in thyroid hormones is not associated with a more frequent incidence of depression [38].

In patients treated with antidepressants, such as SSRIs or venlafaxine, it is important to periodically monitor electrolytes due to the risk of hyponatremia [39]. Due to the risk of the significant dose-dependent prolongation of the QTc interval during pharmacotherapy with SSRIs (especially with citalopram and escitalopram) or tricyclic antidepressants (TCAs), it is advisable to perform, prior to such treatment, an electrocardiographic examination, especially in patients at risk of QTc interval prolongation and those receiving several medicines that affect the potassium channels in the electrical conduction system [40].

It is worth remembering that depressive symptoms may deteriorate co-operation with the physician in the treatment of chronic somatic disorders, including hypertension or diabetes, and worsen compliance with anticoagulant recommendations [41-43]. Oncological patients with symptoms of depression were also less likely to adhere to recommendations [44].

\section{Imaging studies}

The current reports on neuroimaging in unipolar depression provide no explicit data [45]. The criteria for diagnosing depression do not include the results of any neuroimaging studies, but these examinations may be useful in the exclusion of organic disorders in which mood changes may occur. Dougherty and Rauch have proposed guidelines for structural neuroimaging (computed tomography, conventional magnetic resonance) in patients with a sudden change of mental status coexisting with 1 of 3 criteria associated with an increased risk of central nervous system organic changes: 1) age $>50 ; 2$ ) abnormalities in a neurological examination; 3 ) serious head injury in medical history [46]. A structured neuroimaging study should always be considered in suspected depression in elderly patients and those with mood disorders resistant to psychopharmacotherapy.

\section{Questionnaires for depression screening}

In order to perform a rapid screening or objectification of a medical history for depression symptoms, an inexperienced doctor may use available questionnaires to measure the severity of symptoms of mental disorders. The MINI International Neuropsychiatric Questionnaire is the gold standard, but the use of this tool is time-consuming and requires some experience from the investigator [47]. One of the more accessible tools dedicated to family physicians for the diagnosis of psychiatric disorders is PRIME-MD, from which two previously mentioned screening questions for depression have been identified [48]. The Patient Health Questionnaire-9 (PHQ-9), which gathers questions about the symptoms of depression, is its simplified version [24]. This questionnaire, free and also available in Polish, can be completed by most patients within a few minutes, which makes it useful for screening for depression in the practice of a GP (General Practitioner) [49]. It consists of 9 questions about the incidence of particular symptoms (from 0 to 3 points on a 4-point scale) and 1 additional question about the effects of symptoms on the daily functioning of the patient. Previous data indicates that a total of 10 or more scores in the PHQ-9 significantly correlate with a clinical diagnosis of depression [50].

The Beck Depression Scale (current version: BDI-II) is an alternative tool for family physicians, though somewhat more elaborate and time consuming than the PHQ-9. It consists of 21 questions (scored from 0 to 3 ). A score of 14 to 19 points indicates mild depression, 20 to 28 points moderate depression, and 29 to 63 severe depression [26].

\section{Differential diagnosis - bipolar disorder}

Current diagnostic classifications distinguish mono- and bipolar disorders. The presence of symptoms of mania or hypomania is the differentiating factor [51, 52]. In 1996, Akiskal presented a concept of a spectrum of bipolar affective disorders, comprising two subtypes (I and II) of bipolar affective disorder and other bipolar mood disorders [53]. In 2001, Ghaemi et al. proposed the diagnostic criteria for the diagnosis of the bipolar disorder spectrum - a diagnosis that fills the gap between unipolar disorder (depression) and bipolar disorder type II, which in addition to depression, includes hypomania [54].

Reliable medical history taking is the basis for a differential diagnosis of mono- and bipolar disorders. It should provide information on subsequent affective episodes in the patient's life and possible conversions (polar changes) during antidepressant treatment. If a primary care clinician considers a diagnosis for bipolar disorder, the patient should be referred to a psychiatrist to confirm the diagnosis and initiate treatment. Bipolar disorder usually begins during adolescence or early adulthood, thus the examined period is relatively long, and it is possible that the patient will not be able to recall past episodes - particularly those that have been relatively mildly, such as hypomania or subdepression [55]. Diagnostic tools, like the hypomania symptoms questionnaire entitled Hypomania Check List (HCL-32), can be helpful. It is a self-assessment questionnaire, in which the patient answers questions about his/her psychomotor drive, mood and activity. The tool can be used to identify symptoms of bipolar disorder in patients with previously diagnosed depression, or as a screening tool for bipolar affective disorder, also of mild nature [56]. Resistance to treatment of a depressive episode is often due to its unusual character, and not just the wrong choice of drug. Depression in the course of bipolar disorder is characterized by a different psychopathological image than unipolar depression. Perlis et al. have shown that bipolar patients are much more likely to experience tension than depressed 


\begin{tabular}{|c|c|}
\hline SSRI & Other (group) \\
\hline Citalopram 20 mg [67] & Agomelatine $25 \mathrm{mg}\left(\mathrm{MT}_{1} / \mathrm{MT}_{2}\right.$ agonist $-5-\mathrm{HT}_{2 \mathrm{C}}$ antagonist) [68] \\
\hline Escitalopram 10 mg [69] & Duloxetine 60 mg (SNRI) [70, 71] \\
\hline Fluoxetine 20 mg [72] & Mianserin 30 mg (tetracyclic) [73] \\
\hline Fluvoxamine $50 \mathrm{mg}$ [74] & Mirtazapine $30 \mathrm{mg}$ (NaSSA) [75] \\
\hline Paroxetine $20 \mathrm{mg}$ [76] & Moclobemide 300 mg (i-MAO-A) [77] \\
\hline \multirow[t]{8}{*}{ Sertraline $50 \mathrm{mg}[78]$} & Trazodone 150 mg (SARI) [79] \\
\hline & Venlafaxine 75 mg (SNRI) [80] \\
\hline & Amitriptyline 75 mg (TCA) [81] \\
\hline & Clomipramine 150 mg (TCA) [82] \\
\hline & Opipramol 200 mg (TCA) [83] \\
\hline & Doxepine 100 mg (TCA) [84] \\
\hline & Vortioxetine 10 mg (SMS) [85] \\
\hline & Bupropion 150 mg (NDRI) [86] \\
\hline
\end{tabular}

patients, whereas anxiety, which is typical of mood disorders, is more common in patients with bipolar disorder. In turn, insomnia, cognitive symptoms, somatic discomfort, such as difficulty in breathing, gastrointestinal trouble or genitourinary and autonomic nervous system problems, are more frequent in patients with depressive disorders [57]. A differential diagnosis with bipolar disorder requires caution, because pharmacological treatment is different. In order to reduce the risk of phase conversion, the use of antidepressants requires protection with a mood stabilizing drug - classic (normothymic, antiepileptic) or atypical (antipsychotic). At the same time, we should consider faster withdrawal of antidepressants. If one discovers a conversion risk, it is always a good idea to consult with a psychiatrist.

\section{Treatment of depression}

Before starting the treatment of a mild to moderate depressive episode with medication, we should consider, together with the patient, the possibility of non-pharmacological therapies, primarily psychotherapy, especially cognitive-behavioral therapy (CBT). CBT is based on a gradual change in thinking patterns and behaviors. It is a short-term therapy aimed at solving current problems and analyzing present symptoms. CBT can be combined with medication.

Especially when treatment with medication is considered, the choice of the drug needs to be discussed with the patient. It is important to present the planned management, determine the time frame for treatment and warn against adverse reactions that are possible up to two weeks after the start of treatment. We should also make the patient aware of the possibility of withdrawal symptoms and their type if the treatment is too quickly discontinued/abandoned. Proper communication at the initial stage of therapy will significantly increase the chance for the patient to adhere to recommendations, allowing for remission and monitoring of delayed adverse events, such as hyponatremia or upper gastrointestinal bleeding $[58,59]$.

The use of antidepressants in the treatment of mild depression is controversial - psychotherapeutic interventions are recommended if the patient is eager to participate and the method is available [60]. The choice of treatment also depends on the subtype of a depressive episode and the characteristics of the patient, such as age or co-occurrence of other diseases. If a patient shows reluctance to drugs, seasonal or mild depression can be treated with light therapy - a method that can also be used at a home equipped with the proper appliances. Here, CBT psychotherapy, to which the patient should be referred after obtaining information from the psychiatrist, is of great importance.
Selective serotonin reuptake inhibitors (SSRIs) are the drug of choice, although this should be chosen taking into account the spectrum of symptoms and the effects of particular antidepressants, such as activation, silencing, anxiolytic and hypnotic influence, boosting or reduction of appetite, etc. Treatment should be performed using the lowest potentially clinically effective dose (Table 2) [61]. In the initial stage, the most common side effects are anxiety and psychomotor agitation, as well as a higher risk of appearance or intensification of suicidal thoughts - this is especially true in people under the age of 30. The risk of adverse effects can be reduced by using, for a few days, subthreshold doses and increasing the frequency of follow-up visits [62]. After improvement, adequate long-term therapy should be maintained for at least -6 months after first episode and 2 years after the second episode - with the accompanying impaired functioning [60].

Discontinuation of treatment immediately after the symptoms disappear causes recurrence in $50 \%$ of patients [63]. Before withdrawal of the medication, the dose should be gradually reduced (except fluoxetine) in order to decrease the severity of withdrawal symptoms, frequently interpreted by patients as relapse [64]. Patients often report: flu-like symptoms, dizziness increasing during movements, insomnia, irritability, attention deficit disorder (rarely) and memory problems. Different therapeutic behaviors should be considered in a patient with depression and agitation. More sensible treatment is the choice of sedative and anxiolytic medications. Transiently, a benzodiazepine drug may also be introduced, but only for a very limited period of time, as one should remember about the risk of dependence after more than 2 to 4 weeks of use $[65,66]$. It is important to work with family, caretakers or people who are in contact with patients at every stage of treatment, especially in those with major depression and the elderly. An important issue is to assist the patient with regular dosing at the doctor's recommended dosage.

\section{Evaluating the efficacy of the therapy}

During follow-up visits, a medical history should be taken once again, paying particular attention to compliance of treatment, the presence (or duration after the initiation of treatment) of adverse reactions and clinical effects. Figures 2 and 3 shows the clinical course, including management based on the effect achieved and clinical tips. However, it should be borne in mind that diagnostic criteria that help physicians make a diagnosis have been created on computational algorithms developed years ago. As research suggest, patients' expectations for the behavior of a physician are different. According to Zimmer- 


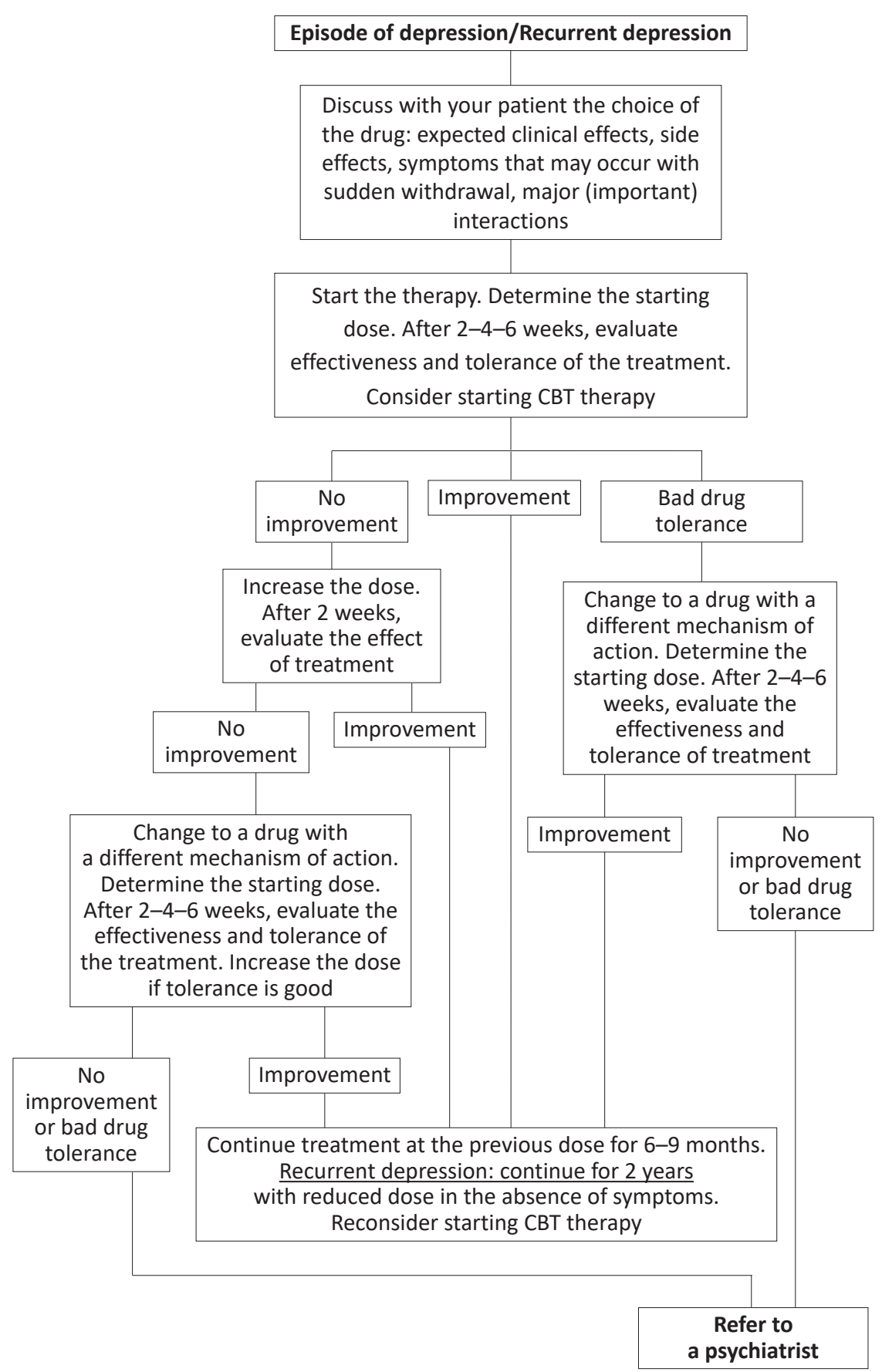

Figure 2. Clinical management based on the effect achieved

man et al., the importance of patients' expectations is as follows: 1) the presence of mental health symptoms (e.g. optimism, vigor, self-confidence); 2 ) sense of normality; 3) return to normal functioning at work, home; 4) the feeling of emotional control; 5) relationships with family and friends and the ability to enjoy them; 6) the lack of symptoms of depression - as the last element of the psychopathological picture [87]. Thus, quality of life seems to be more important to patients than the lack of illness. It is worth remembering this when taking a medical history during follow-up visits in the following weeks of treatment. Specific questionnaires like the PHQ-9 [24] or BDI [26] can be used to monitor the effectiveness of treatment.

\section{Conclusions}

The need for early diagnosis and an early start of effective therapy for depressive disorders in primary care patients by family physicians is obvious. However, the multitude of factors that should be assessed in a physical examination and laboratory testing reduces the amount of time required to take a thorough and multi-directional medical history in the primary care setting. However, it is not necessary to do all this within the first consultation. At this stage of diagnostic management, screening tools with proven psychometric parameters are useful tools to guide the physician's taking of a medical history, indicating the main problematic areas, before deciding whether to start psychotherapeutic or pharmacological treatment. They also allow doctors to evaluate the severity of symptoms, monitor progress and make it easier to decide whether treatment can be safely performed in primary care or if one needs referral to a psychiatric setting. To some extent, these instruments also allow for an initial differential diagnosis between mono- and bipolar disorders. This is particularly important for the latter, because their treatment requires clinical experience, more intensive monitoring of therapeutic effects and supervision of the frequent use of drugs in this group. 


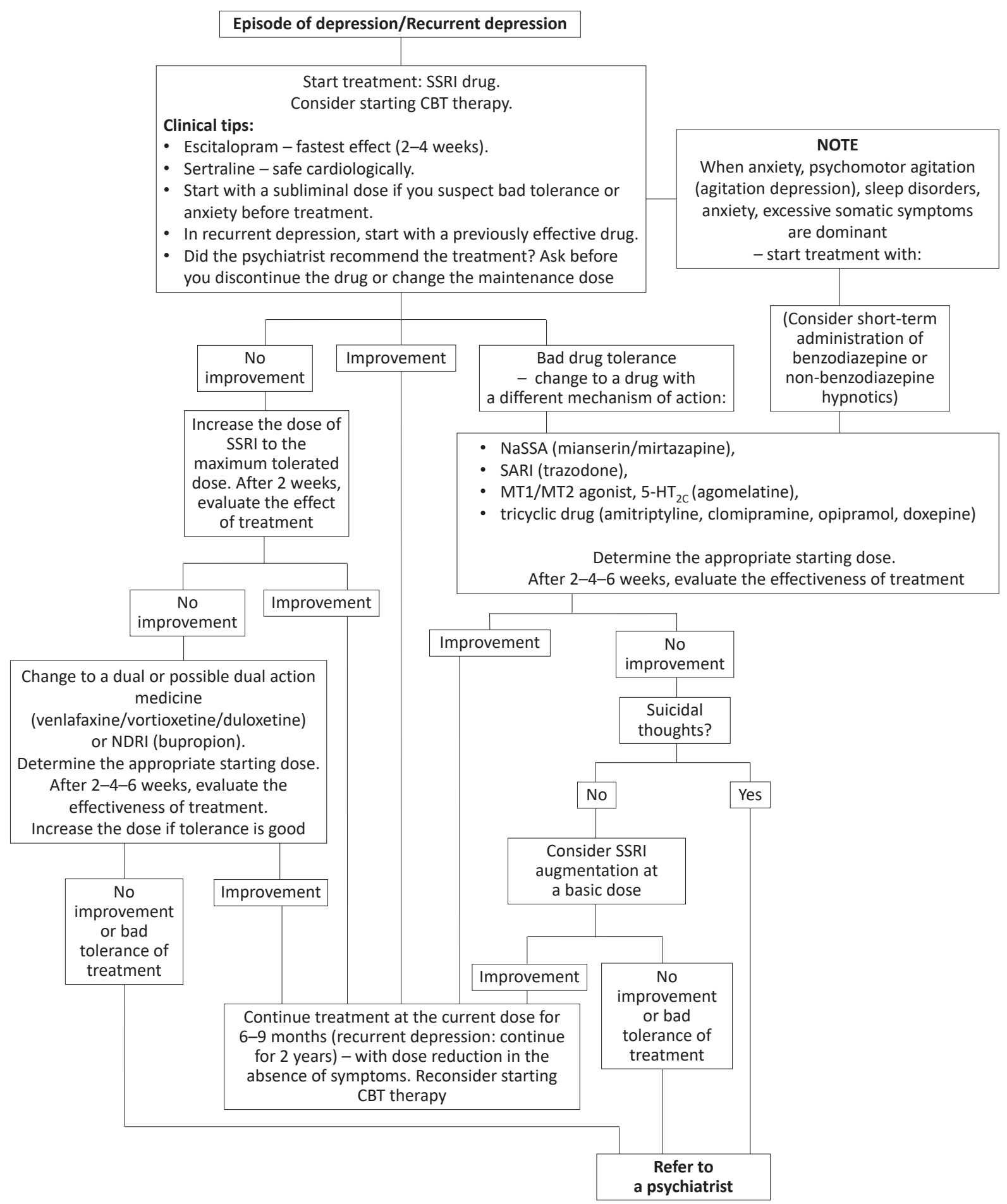

Figure 3. Clinical management - clinical tips

In contrast to bipolar disorders, most patients with unipolar mood disorders can be treated within the primary care setting. Often patients with mood disorders are seeking help from their well-known family physicians and often do not require a psychiatric consultation.

It should be emphasized that the vast majority of primary care patients report symptoms of psychosomatic disorders that are aggravated by daily stressful situations. Before starting diagnostic and therapeutic actions, it is advisable to extend the consultation of these patients to at least 15-20 minutes, analyze their family, financial and professional situation and convince them to use stress management techniques, such as relaxation techniques, psycho- and sociotherapy, as well as to persuade them to consider sports, change their perception of the environment and avoid negative habits in life and nutrition. If there is no improvement of the depressive symptoms after 2 to 4 weeks, other therapeutic strategies should be considered.

Currently, psychotropic drugs commonly used in mood disorders have a wide margin of safety and, if well tolerated, are highly effective in reducing the severity of psychopathological symptoms and can be safely prescribed in primary care to improve the daily functioning of patients. 


\section{References}

1. Murray CJL, Lopez AD, eds. The Global Burden of Disease: a comprehensive assessment of mortality and disability from diseases, injuries, and risk factors in 1990 and projected to 2020. Cambridge: Harvard University Press; 1996.

2. Murray CJ, Vos T, Lozano R, et al. Disability-adjusted life years (DALYs) for 291 diseases and injuries in 21 regions, 1990-2010: a systematic analysis for the Global Burden of Disease Study 2010. Lancet 2012; 380(9859): 2197-2223.

3. Alonso J, Angermeyer MC, Bernert S, et al. Prevalence of mental disorders in Europe: results from the European Study of the Epidemiology of Mental Disorders (ESEMeD) project. Acta Psychiatr Scand 2004; Suppl. 109(420): 21-27.

4. Bromet EJ, Gluzman SF, Paniotto VI, et al. Epidemiology of psychiatric and alcohol disorders in Ukraine: findings from the Ukraine World Mental Health survey. Soc Psychiatry Psychiatr Epidemiol 2005; 40(9): 681-690.

5. Moskalewicz J, Kiejna A, Wojtyniak B, eds. Kondycja psychiczna mieszkańców Polski. Warszawa: IPiN; 2012: 186 (in Polish).

6. Roca M, Gili M, Garcia-Garcia M, et al. Prevalence and comorbidity of common mental disorders in primary care. J Affect Disord 2009; 119(1-3): 52-58.

7. Ansseau M, Dierick M, Buntinkx F, et al. High prevalence of mental disorders in primary care. J Affect Disord 2004; 78(1): 49-55.

8. Montago CB. Recognition and treatment of depression in a primary care setting. J Clin Psychiatry 1994; 55(Suppl.): 18-34; discussion 35-37.

9. Scott KM, Bruffaerts R, Tsang A, et al. Depression-anxiety relationships with chronic physical conditions: results from the World Mental Health Surveys. J Affect Disord 2007; 103(1-3): 113-120.

10. Katon W, Lin EHB, Kroenke K. The association of depression and anxiety with medical symptom burden in patients with chronic medical illness. Gen Hosp Psychiatry 2007; 29(2): 147-155.

11. Härter $\mathrm{M}$, Baumeister $\mathrm{H}$, Reuter $\mathrm{K}$, et al. Increased 12-month prevalence rates of mental disorders in patients with chronic somatic disease. Psychother Psychosom 2007; 76(6): 354-360.

12. Dudek D, Siwek M. Współistnienie chorób somatycznych i depresji. Psychiatria 2007; 4(1): 17-24 (in Polish).

13. Barley EA, Murray J, Walters $P$, et al. Managing depression in primary care: a meta-synthesis of qualitative and quantitative research from UK to identify barriers and facilitators. BMC Family Practice 2011; 12: 47-57.

14. Egede LE. Major depression in individuals with chronic medical disorders: prevalence, correlates and association with health resource utilization, lost productivity and functional disability. Gen Hosp Psychiatry 2007; 29(5): 409-416.

15. Simon GE, Katon WJ, Lin EH, et al. Cost-effectiveness of systematic depression treatment among people with diabetes mellitus. Arch Gen Psychiatry 2007; 64(1): 65-72.

16. Scott KM, Von Korkoff M, Alonso J, et al. Mentalphysical co-morbidity and its relationship with disability: results from the World Mental Health Surveys. Psychol Med 2009; 39(1): 33-43.

17. Dróżdż W, Wojnar M, Araszkiewicz A, et al. The study of the prevalence of depressive disorders in primary care patients in Poland. Wiad Lek 2007; 60(3-4): 109-113.

18. Tylee A, Gandhi P. The importance of somatic symptoms in depression in primary care. Prim Care Companion J Clin Psychiatry 2005; 7(4): 167-176.

19. Klasyfikacja zaburzeń psychicznych i zaburzeń zachowania w ICD-10. Badawcze kryteria diagnostyczne. Kraków, Warszawa: Uniwersyteckie Wydawnictwo Medyczne „Vesalius”, Instytut Psychiatrii i Neurologii; 1998 (in Polish).

20. Whooley MA, Avins AL, Miranda J, et al. Case-finding instruments for depression: two questions are as good as many. J Gen Intern Med 1997; 12(7): 439-445.

21. Arroll B, Khin N, Kerse N. Screening for depression in primary care with two verbally asked questions: cross sectional study. BMJ 2003; 327(7424): 1144-1146.

22. Arroll B, Goodyear-Smith F, Kerse N, et al. Effect of the addition of a "help" question to two screening questions on specificity for diagnosis of depression in general practice: diagnostic validity study. BMJ 2005; 331(7521): 884.

23. Mitchell AJ, Coyne JC. Do ultra-short screening instruments accurately detect depression in primary care? A pooled analysis and metaanalysis of 22 studies. Br J Gen Pract 2007; 57(535): 144-151.

24. Kroenke K, Spitzer RL, Williams JB. The PHQ-9: validity of a brief depression severity measure. J Gen Intern Med 2001; 16(9): 606-613.

25. Zigmond AS, Snaith RP. The hospital anxiety and depression scale. Acta Psychiatr Scand 1983; 67(6): 361-370.

26. Beck AT, Steer RA, Ball R, et al. Comparison of Beck Depression Inventories-IA and-II in psychiatric outpatients. J Pers Assess 1996; 67(3): 588-597.

27. Sutor B. Major depression in medically ill patients. Mayo Clin Proc 1998; 73(4): 329-337.

28. Lehtinen V, Joukamaa M. Epidemiology of depression: prevalence, risk factors and treatment situation. Acta Psychiatr Scand 1994; Suppl. 377: 7-10.

29. Kendler KS, Gardner CO, Neale MC, et al. Genetic risk factors for major depression in men and women: similar or different heritabilities and same or partly distinct genes? Psychol Med 2001; 31(4): 605-616.

30. Kranzler HR, Rosenthal RN. Dual diagnosis: alcoholism and co-morbid psychiatric disorders. Am J Addict 2003; 12(Suppl. 1): S26-S40.

31. Bovasso GB. Cannabis abuse as a risk factor for depressive symptoms. Am J Psychiatry 2001; 158(12): 2033-2037.

32. Davis L, Uezato A, Newell JM, et al. Major depression and comorbid substance use disorders. Curr Opin Psychiatry 2008; 21(1): 14-18.

33. Kiejna A, Piotrowski P, Adamowski T, et al. The prevalence of common mental disorders in the population of adult Poles by sex and age structure - an EZOP Poland study. Psychiatr Pol 2015; 49(1): 15-27.

34. Hawton K, Casañas I, Comabella C, et al. Risk factors for suicide in individuals with depression: a systematic review. J Affect Disord 2013; 147(1-3): 17-28.

35. Masiak M, Przychoda J. M.I.N.I. Mini International Neuropsychiatric Interview. Polish Version 5.0.0. Lublin: Katedra i Klinika Psychiatrii Akademii Medycznej; 1998 (in Polish).

36. Rouchell AM. Major depression in primary care. Ochsner J 2000; 2(2): 79-84.

37. Hage MP, Azar ST. The link between thyroid function and depression. J Thyroid Res 2012; 2012: 590648, doi: 10.1155/2012/590648.

38. Dayan CM, Panicker V. Hypothyroidism and depression. Eur Thyroid J 2013; 2(3): 168-179, doi: 10.1159/000353777.

39. De Picker L, Van Den Eede F, Dumont G, et al. Antidepressants and the risk of hyponatremia: a class-by-class review of literature. Psychosomatics 2014; 55(6): 536-547.

40. Beach SR, Kostis WJ, Celano CM, et al. Meta-analysis of selective serotonin reuptake inhibitor-associated QTc prolongation. J Clin Psychiatry 2014; 75(5): e441-e449.

41. Wang PS, Bohn RL, Knight E, et al. Noncompliance with antihypertensive medications: the impact of depressive symptoms and psychosocial factors. J Gen Intern Med 2002; 17(7): 504-511. 
42. Gentil L, Vasiliadis HM, Préville M, et al. Adherence to oral antihyperglycemic agents among older adults with mental disorders and its effect on health care costs, Quebec, Canada, 2005-2008. Prev Chronic Dis 2015; 12: 150412, doi: http://dx.doi.org/10.5888/ pcd12.150412.

43. Michal M, Prochaska JH, Ullmann A, et al. Relevance of depression for anticoagulation management in a routine medical care setting: results from the ThrombEVAL study program. J Thromb Haemost 2014; 12(12): 2024-2033.

44. Mausbach BT, Schwab RB, Irwin SA. Depression as a predictor of adherence to adjuvant endocrine therapy (AET) in women with breast cancer: a systematic review and meta-analysis. Breast Cancer Res Treat 2015; 152(2): 239-246.

45. Müller VI, Cieslik EC, Serbanescu I, et al. Altered brain activity in unipolar depression revisited: meta-analyses of neuroimaging studies. JAMA Psychiatry 2017; 74(1): 47-55.

46. Dougherty DD, Rauch SL, eds. Psychiatric neuroimaging research: contemporary strategies. Washington DC: American Psychiatric Publishing Inc.; 2001.

47. Sheehan DV, Lecrubier Y, Sheehan KH, et al. The Mini-International Neuropsychiatric Interview (M.I.N.I.): the development and validation of a structured diagnostic psychiatric interview for DSM-IV and ICD-10. J Clin Psychiatry 1998; 59(Suppl. 20): 22-33, quiz 34-57.

48. Tamburrino MB, Lynch DJ, Nagel RW, et al. Primary Care Evaluation of Mental Disorders (PRIME-MD) screening for minor depressive disorder in primary care. Prim Care Companion J Clin Psychiatry 2009; 11(6): 339-343.

49. Tomaszewski K, Zarychta M, Bieńkowska A, et al. Validation of the Patient Health Questionnaire-9 Polish version in the hospitalised elderly population. Psychiatr Pol 2011; 45(2): 223-233.

50. Arroll B, Goodyear-Smith F, Crengle S, et al. Validation of PHQ-2 and PHQ-9 to screen for major depression in the primary care population. Ann Fam Med 2010; 8(4): 348-353, doi: 10.1370/afm.1139.

51. Perris C. A study of bipolar (manic-depressive) and unipolar recurrent depressive psychoses. Genetic investigation. Acta Psychiatr Scand 1966; 42(Suppl. 194): 15-44.

52. Angst J. Zur Atiologie und Nosologie endogener depressiver Psychosen. Berlin: Springer; 1966.

53. Akiskal HS. The prevalent clinical spectrum of bipolar disorders: beyond DSM-IV. J Clin Psychopharmacol 1996; 16(Suppl. 1): 4-14.

54. Ghaemi SN, Ko JY, Goodwin FK. The bipolar spectrum and the antidepressant view of the world. J Psychiatr Pract 2001; 7(5): $287-297$.

55. Merikangas KR, Jin R, He JP, et al. Prevalence and correlates of bipolar spectrum disorder in the world mental health survey initiative. Arch Gen Psychiatry 2011; 68(3): 241-251.

56. Łojko D, Rybakowski J, Dudek D, et al. Hypomania Check List (HCL-32) - kwestionariusz objawów hipomanii: charakterystyka i zastosowanie. Psychiatr Pol 2010; 44(1): 39-46 (in Polish).

57. Perlis RH, Brown E, Baker RW, et al. Clinical features of bipolar depression versus major depressive disorder in large multicenter trials. Am J Psychiatry 2006; 163(2): 225-231.

58. Jacob S, Spinler SA. Hyponatremia associated with selective serotonin-reuptake inhibitors in older adults. Ann Pharmacother 2006; 40(9): 1618-1622.

59. Dalton SO, Johansen C, Mellemkjaer L, et al. Use of selective serotonin reuptake inhibitors and risk of upper gastrointestinal tract bleeding: a population-based cohort study. Arch Intern Med 2003; 163(1): 59-64.

60. National Institute of Clinical Excellance. Depression: management of depression in primary and secondary care - clinical guidance 2004 [cited: 13.04.2017]. Available from URL: http://www.nice.org.uk.

61. Committee on Safety of Medicines. Report of the CSM expert working group on the safety of selective serotonin reuptake inhibitor antidepressants 2004 [cited: 13.04.2017]. Available from URL: http://www.mhra.gov.uk.

62. NICE. 1.8 Sequencing treatments after initial inadequate response [cited: 13.04.2017]. Available from URL: https://www.nice.org.uk/ guidance/cg90/chapter/1-Guidance\#treatment-choice-based-on-depression-subtypes-and-personal-characteristics.

63. Loonen AJ, Peer PGM, Zwanikken GJ. Continuation and maintenance therapy with antidepressive agents. Meta-analysis of research. Pharm Weekley Sci 1991; 13(4): 167-175.

64. Haddad PM. Antidepressant discontinuation syndromes. Drug Saf 2001; 24(3): 183-197.

65. Ashton H. The diagnosis and management of benzodiazepine dependence. Curr Opin Psychiatry 2005; 18(3): 249-255.

66. Basińska A. Zapobieganie uzależnieniom od benzodiazepin i nie-benzodiazepinowych leków nasennych - regulacje prawne i zalecenia medyczne. Terapia 2011; 19: 66-70 (in Polish).

67. Montgomery SA, Pedersen V, Tangh øj P, et al. The optimal dosing regimen for citalopram - a meta-analysis on nine placebo-controlled studies. Int Clin Psychopharmacol 1994; 9(Suppl. 1): 35-40.

68. Kennedy SH, Avedisova A, Belaïdi C, et al. Sustained efficacy of agomelatine $10 \mathrm{mg}, 25 \mathrm{mg}$, and $25-50 \mathrm{mg}$ on depressive symptoms and functional outcomes in patients with major depressive disorder. A placebo-controlled study over 6 months. Eur Neuropsychopharmacol 2016; 26(2): 378-389, doi: 10.1016/j.euroneuro.2015.09.006.

69. Burke WJ, Gergel I, Bose A. Fixed-dose trial of the single isomer SSRI escitalopram in depressed outpatients. J Clin Psychiatry 2002; 63(4): 331-336.

70. Goldstein DJ, Lu Y, Detke MJ, et al. Duloxetine in the treatment of depression, a double-blind placebo-controlled comparison with paroxetine. J Clin Psychopharmacol 2004; 24(4): 389-399.

71. Detke MJ, Lu Y, Goldstein DJ, et al. Duloxetine, $60 \mathrm{mg}$ once daily for major depressive disorder: a randomized double-blind placebocontrolled trail. J Clin Psychiatry 2002; 63(4): 308-315.

72. Altamura AC, Montgomery SA, Wernicke JF. The evidence for $20 \mathrm{mg}$ a day of fluoxetine as the optimal dose in the treatment of depression. Br J Psychiatry 1988; 3(Suppl.): 109-112.

73. Wakeling A. Efficacy and side effects of mianserin, a tetracyclic antidepressant. Postgrad Med J 1983; 59(690): $229-231$.

74. Walczak DD, Apter JT, Halikas JA, et al. The oral dose-effect relationship for fluvoxamine: a fixed-dose comparison against placebo in depressed outpatients. Ann Clin Psychiatry 1996; 8(3): 139-151.

75. Van Moffaert M, de Wilde J, Vereecken A, et al. Mirtazapine is more effective than trazodone: a double-blind controlled study in hospitalized patients with major depression. Int Clin Psychopharmacol 1995; 10(1): 3-9.

76. Dunner DL, Dunbar GC. Optimal dose regimen for paroxetine. J Clin Psychiatry 1992; 53(Suppl.): 21-26.

77. Priest RG, Schmid-Burgk W. Moclobemide in the treatment of depression. Rev Contemp Pharmacother 1994; 5: 35-43.

78. Moon CAL, et al. A double-blind comparison of sertraline and clomipramine in the treatment of major depressive disorder and associative anxiety in general practice. J Psychopharmacol 1994; 8: 171-176.

79. Brogden RN, Heel RC, Speight TM, et al. Trazodone: a review of its pharmacological properties and therapeutic use in depression and anxiety. Drugs 1981; 21(6): 401-429.

80. Feigher JP, Entsuah AR, McPherson MK. Efficacy of once-daily venlafaxine extended release (XR) for symptoms of anxiety in depressed outpatients. J Affect Disord 1998; 47(1-3): 55-62.

81. Gravem A, Amthor KF, Astrup C, et al. A double-blind comparison of citalopram (Lu 10-171) and amitriptyline in depressed patients. Acta Psychiatr Scand 1987; 75(5): 478-486. 
82. Andersen J, Bech P, Benjaminsen S, et al. Citalopram: clinical effect profile in comparison with clomipramine. A controlled multicentre study. Psychopharmacology 1986; 90: 131-138.

83. Volz HP, Möller HJ, Reimann I, et al. Opipramol for the treatment of somatoform disorders results from a placebo-controlled trial. D Eur Neuropsycopharmacol 2000; 10: 211.

84. Kupfer DJ. The pharmacological management of depression. Dialogues Clin Neurosci 2005; 7(3): 191-205.

85. Baldwin DS, Chrones L, Florea I, et al. The safety and tolerability of vortioxetine: analysis of data from randomized placebo-controlled trials and open-label extension studies. J Psychopharmacol (Oxford) 2016; 30(3): 242-252, doi: 10.1177/0269881116628440.

86. Maneeton N, Maneeton B, Eurviriyanukul K, et al. Efficacy, tolerability, and acceptability of bupropion for major depressive disorder: a meta-analysis of randomized-controlled trials comparison with venlafaxine. Drug Des Devel Ther 2013; 7: 1053-1062, doi: 10.2147/ DDDT.S46849.

87. Zimmerman M, McGlinchey JB, Posternak MA, et al. How should remission from depression be defined? The depressed patient's perspective. Am J Psychiatry 2006; 163(1): 148-150.

Tables: 2

Figures: 3

References: 87

Received: 15.07.2017

Revised: 22.07.2017

Accepted: 22.07.2017

Address for correspondence:

Patryk Piotrowski, MD, PhD

Katedra Psychiatrii UM

Wybrzeże L. Pasteura 10

50-367 Wrocław

Polska

Tel.: + 4871 784-16-00

E-mail: patryk.piotrowski@umed.wroc.pl 